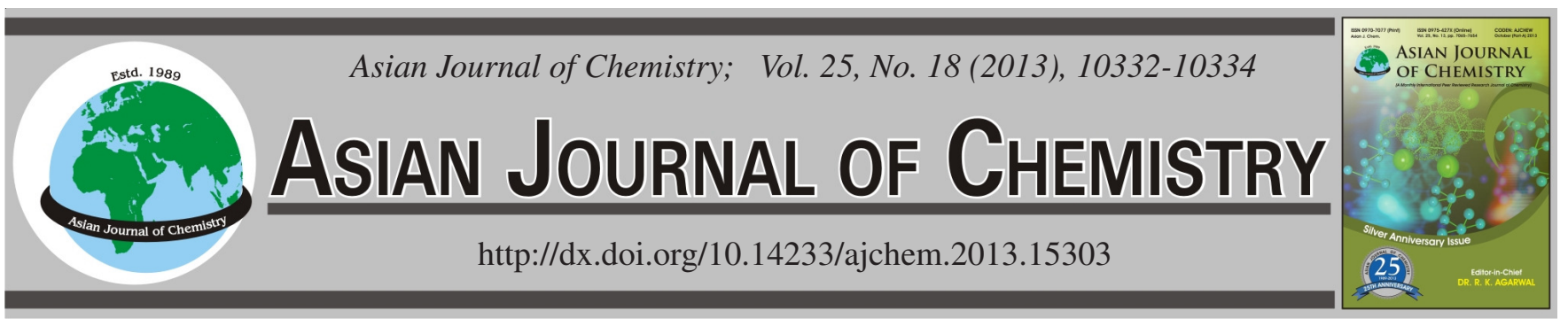

\title{
Determination of Antioxidant Activity of Total Flavonoids from Tussilago farfara by Flow Injection Chemiluminescence
}

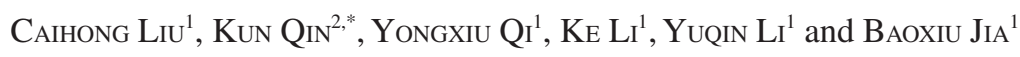

${ }^{1}$ College of Pharmaceutical, Taishan Medical University, Tai'an 271016, P.R. China

${ }^{2}$ College of Chemistry and Chemical Engineering, Taishan Medical University, Tai'an 271016, P.R. China

*Corresponding author: E-mail: liuch7688@163.com

(Received: 11 February 2013;

Accepted: 14 November 2013)

AJC-14396

\begin{abstract}
The antioxidant activity of total flavonoids from Tussilago farfara in vitro was determinated by flow injection analysis chemiluminescence. The determination was based on the inhibition effect of their natural antioxidants on the free radical-induced luminol chemiluminescence. Ascorbic acid was used as antioxidant standard. At the optimum operational conditions, the antioxidant activity was measured by plotting the inhibition percentage versus the content of samples to calculate the $\mathrm{IC}_{50}$. The results revealed that the flavonoids from Tussilago farfara showed stronger free radical scavenging activity on superoxide $\left(\mathrm{O}_{2}^{-}\right)$than ascorbic acid. It is suggested that Tussilago farfara is a good natural antioxidant and has the potential to be used in the manufacturing of foods and medicines.
\end{abstract}

Key Words: Flow injection chemiluminescence, Flavonoids from Tussilago farfara, Antioxidation.

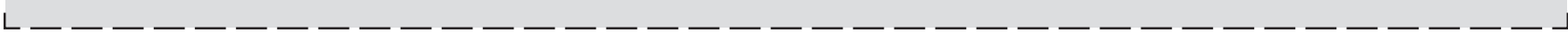

\section{INTRODUCTION}

Tussilago farfara L. is a member of the Asteraceae family and flower buds of this plant have been used as a traditional Chinese herbal medicine for the treatment of bronchitic and asthmatic conditions $^{1}$. T. farfara has been reported to have inhibitory activity against nitric oxide synthase ${ }^{2}$, antimicrobial activity ${ }^{3}$ and antagonistic activity on platelet-activating factor receptor ${ }^{4}$. It contains polysaccharides ${ }^{5}$, alkaloids ${ }^{6}$, flavonoids ${ }^{7}$ substances.

It is well known that flavonoids in plants can be applied in medical field with its antioxidant activitives. The role of antioxidants seems contribute to the interaction between flavonoids in plants, which are present in different combinations ${ }^{8}$. The synergistic interaction of flavonoids may be an important factor of the overall antioxidant activity of plant-derived products, which could be more distinct than the activity of individual compounds. Antioxidant activity of T. farfara has already been studied $^{7,9}$, but none of the previously described antioxidant capacity of the total flavonoids. Therefore, in this study, we attempted to characterize the antioxidant and free radical scavenging activities of the total flavonoids from $T$. farfara in vitro.

To evaluate the potential antioxidant effects of substances, many in vitro procedures are employed ${ }^{10,11}$. In the present study, we evaluate the antioxidative effect of the total flavonoids from T. farfara by using a flow injection analysis method (FIA), which is a fast, accurate system for monitoring chemiluminescence $(\mathrm{CL})$ reactions induced by reactive oxygen species $(\mathrm{ROS})^{12}$. The ascorbic acid was used to positive control.

\section{EXPERIMENTAL}

The flower buds of T. farfara was purchased from Taian Pharmacy in Shandong Province, China and were identified by pharmacist LI Tong-De. Voucher specimens have been deposited in the College of Pharmacy, Taishan Medical University. Luminol was purchased from Sigma. Rutin (reference standards) was purchased from National Institutes for Food and Drug Control. Water was prepared with doubly distilled. Other chemicals were of analytical-reagent grade and were used as supplied unless otherwise stated.

Buffer solutions, pyrogallol solution, potassium ferrocyanide solution, luminol solution and $\mathrm{H}_{2} \mathrm{O}_{2}$ solution, were stored at $-4{ }^{\circ} \mathrm{C}$. Prior to use they were allowed to reached room temperature. All the luminol solutions were protected from light by a foil wrapper. All the antioxidants solutions were freshly prepared and diluted in doubly distilled water.

The ultra weak luminescence analyzer (IFFM-D, Remex Electronic Institute Limited Co., Xi'an, China), equipped with an eight-channel rotary injection valve and two peristaltic pumps was used to measure chemiluminescence. The photomultiplier tube was used to detect chemiluminescence signal in the flow cell. An IFFL-D flow-injection chemiluminescence 
analysis software system (Xi'an Remex Electronic equipment Corporate, Xi'an, China) was used to analysis chemiluminescence signal in the flow cell.

Procedures: The flow injection manifold used has been previously described ${ }^{13}$ as shown in Fig.1. According to this configuration, the oxidant stream was merged with a water carrier immediately, and then the combined flow was merged with luminol immediately before the flow cell. Thus, a constant chemiluminescence signal was continuously detected when only water was flowing on the $\mathrm{S}$ channel (maximum intensity $\left(I_{\max }\right)$. When antioxidant was injected into $\mathrm{S}$ channel, the attenuation of the chemiluminescence emission signal (minimum intensity $\left(\mathrm{I}_{\mathrm{min}}\right)$ was detected.

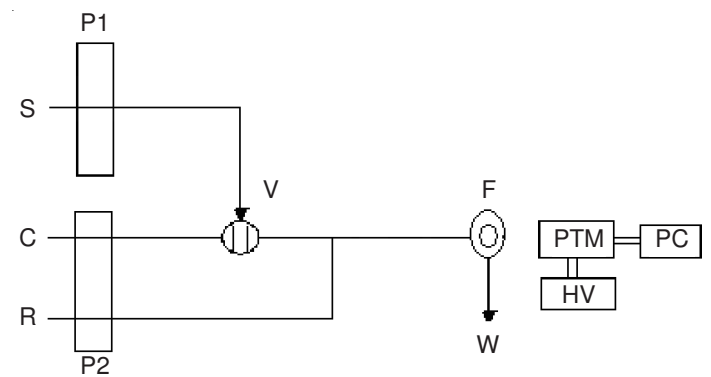

Fig. 1. Diagram of the flow system used in the experiments. S, sample (antioxidant or water ); C,oxidant ; R, luminol; P, Peristaltic pump; $\mathrm{V}$, injection valve; F, chemiluminescence flow cell; PMT, photomultiplier tube; HV, negative high-voltage supply; PC, computer; $\mathrm{W}$, waste solution

The chemiluminescence is measured as the photomultiplier output in millivolt; the effects of antioxidants were measured by the depression of the signal from its uninhibited level and were expressed as a percentage attenuation of the chemiluminescence maximum due to the antioxidant. By plotting the chemiluminescence intensity against the time, the maximum and minimum intensity were determined and the percentage of inhibition was determined in each case using the following equation:

$$
\text { Inhibitiion }(\%)=\left[\frac{\left(I_{\max }-I_{\min }\right)}{I_{\max }}\right] \times 100 \%
$$

Inhibition curves are represented by plotting the content of samples in each solution against the \% Inhibition. These curves are used to determine the $\mathrm{IC}_{50}$ that represents the amount of sample that produced a chemiluminescence inhibition of $50 \%$.

Results are the mean values of three replicates of the same sample. Statistical analysis was performed using analysis of variance.

Superoxide $\left(\mathrm{O}_{2}^{-\bullet}\right)$ scavenging method: Superoxide radicals were generated by the autoxidation of pyrogallol which reacted with luminous and gave the chemiluminescence. The concentration of the radicals was not known and is represented by the chemiluminescence intensity. The optimal working conditions were $0.5 \mathrm{mmol} / \mathrm{L}$ pyrogallol in $1 \mathrm{mmol} / \mathrm{L}$ hydrochloric acid, $0.40 \mathrm{mmol} / \mathrm{L}$ luminol and $0.10 \mathrm{~mol} / \mathrm{L}$ carbonate buffer at $\mathrm{pH} 10$.

Hydroxyl radicals $\left({ }^{\circ} \mathrm{OH}\right)$ scavenging method: Hydroxyl radicals were generated by Fenton reaction. Luminol is luminous synergistic agent. The concentration of the radicals was not known and is represented by the chemiluminescence intensity. The optimal working conditions were $0.26 \mathrm{mmol} / \mathrm{L}$ potassium ferrocyanide, $0.10 \mathrm{mmol} / \mathrm{L}$ luminol, $0.20 \%$ hydrogen peroxide and $\mathrm{KH}_{2} \mathrm{PO}_{4}-\mathrm{NaOH}$ buffer at $\mathrm{pH} 7.20$.

Hydrogen peroxide $\left(\mathrm{H}_{2} \mathrm{O}_{2}\right)$ scavenging method: In alkaline conditions, hydrogen peroxide oxidates luminol to shine and the luminous intensity is proportional to the content of hydrogen peroxide, the decrease chemiluminescence intensity can reflect the scavenging ability of samples. Hydrogen peroxide was prepared daily and protected from light by a foil wrapper. The optimal working conditions were $0.20 \% \mathrm{H}_{2} \mathrm{O}_{2}, 0.20 \mathrm{mmol} / \mathrm{L}$ luminol and $0.10 \mathrm{~mol} / \mathrm{L}$ carbonate buffer at $\mathrm{pH} 9.60$.

Sample pre-treatment of $T$. farfara: Air-dried flower buds of $T$. farfara $(2.0 \mathrm{~g})$ were extracted by $50 \%$ ethanol $(40 \mathrm{~mL})$ at $80^{\circ} \mathrm{C}$ for $1 \mathrm{~h}$ and then filtrated immediately. After cooling at room temperature, the extracts were diluted to $100 \mathrm{~mL}$. The total flavonoids content of the samples was determined spectrophotometrically, A calibrating curve was plotted using rutin as standard. The total flavonoids content of $T$. farfara extract was $6.3 \%$, the content of sample solution was $1.26 \mathrm{~g} / \mathrm{L}$.

\section{RESULTS AND DISCUSSION}

Superoxide: Fig. 2 shows a typical chart recorder trace of a continuous chemiluminescence signal from pyrogallol and luminol ( $\mathrm{pH} 10)$ and the effect of a sequence of injections of water and the extract of T. farfara.

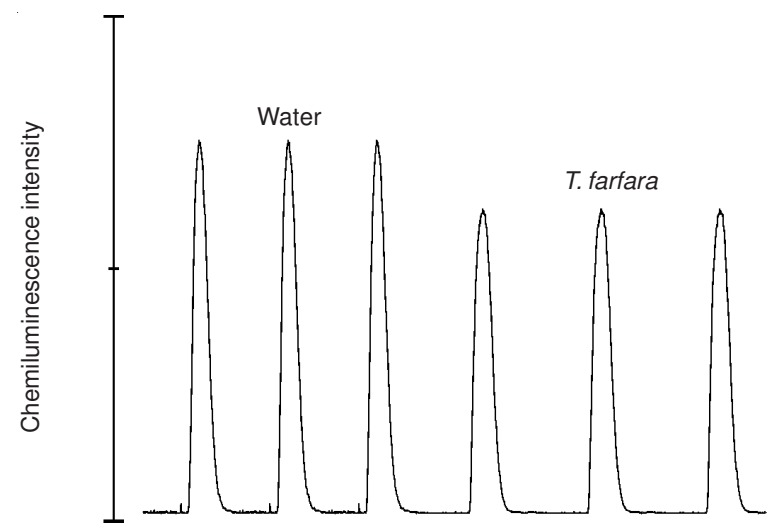

Fig. 2. Effect of water and the extract of T. farfara on chemiluminescence intensity

The chemiluminescence intensity was inhibited by the extract of $T$. farfara and the total flavonoids from $T$. farfara had the scavenging activity on $\mathrm{O}_{2}^{-\bullet}$ (Fig. 2). Curves in Fig. 3 were used to determine the $\mathrm{IC}_{50}$. Low values of $\mathrm{IC}_{50}$ implied higher antioxidant capacity. The $\mathrm{IC}_{50}$ value were 9.93 and 42.20 $\mu \mathrm{g} / \mathrm{mL}$ for the extract of $T$. farfara and ascorbic acid, respectively (Table-1). Thus the antioxidant potency order is $T$. farfara extract $>$ ascorbic acid.

TABLE-1

ANTIOXIDATION OF T. farfara AND ASCORBIC ACID

\begin{tabular}{lccc}
\hline \multirow{2}{*}{ Samples } & \multicolumn{3}{c}{$\mathrm{IC}_{50}(\mathrm{mg} / \mathrm{L})$} \\
\cline { 2 - 4 } & $\mathrm{O}_{2}^{\bullet}$ & ${ }^{\bullet} \mathrm{OH}$ & $\mathrm{H}_{2} \mathrm{O}_{2}$ \\
\hline Ascorbic acid & 42.20 & 12.42 & 0.34 \\
T. farfara & 9.93 & 14.15 & 0.92 \\
\hline
\end{tabular}




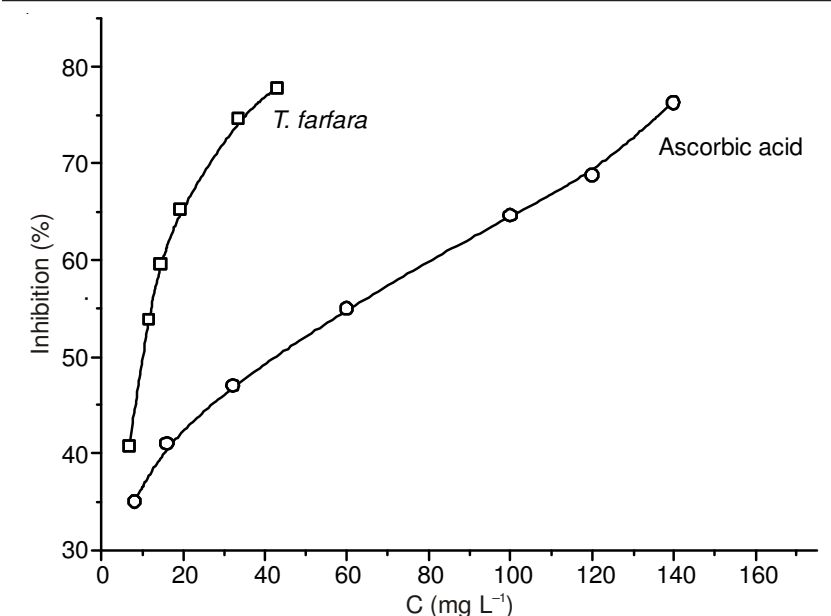

Fig. 3. Scavenging ability on $\mathrm{O}_{2}^{-\bullet}$ of ascorbic acid and T. farfara. LSD at $p$ $<0.05$

Hydroxyl radical: Ferrous iron-induced chemiluminescence was inhibited by $T$. farfara extract and ascorbic acid in a concentration-dependent manner, as shown in Fig. 4. The $\mathrm{IC}_{50}$ value were 14.15 and $12.42 \mu \mathrm{g} / \mathrm{mL}$ for $T$ farfara extract and ascorbic acid, respectively (Table-1). The antioxidant potency order is ascorbic acid $>T$. farfara extract.

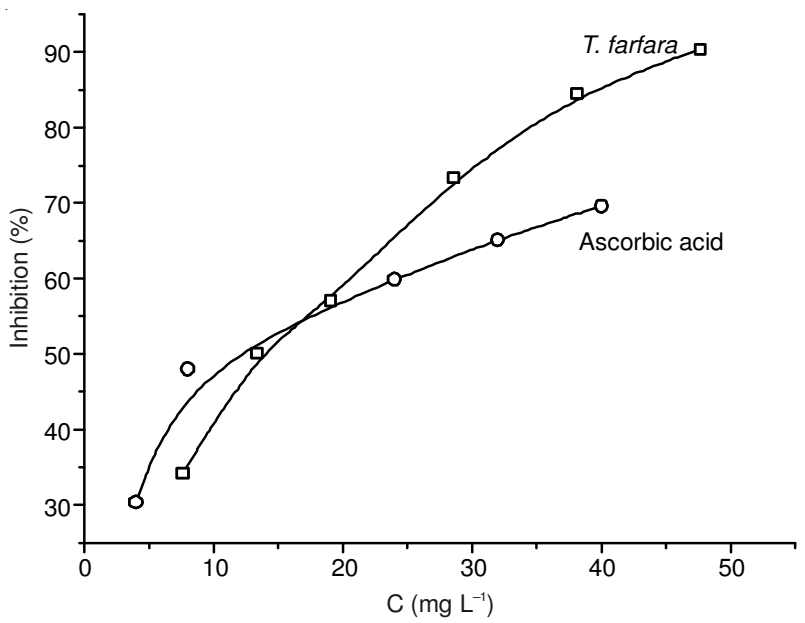

Fig. 4. Scavenging ability on ${ }^{\circ} \mathrm{OH}$ of ascorbic acid and T. farfara. LSD at $p<0.05$

Hydrogen peroxide: As summarized in Fig. 5, the $\mathrm{H}_{2} \mathrm{O}_{2-}$ dependent chemiluminescence signal was inhibited by either T. farfara extract or ascorbic acid. The scavenging activity of T. farfara extract or ascorbic acid was found in a concentrationdependent manner. The results show that the activity of ascorbic acid was stronger than those of T. farfara extract. The antioxidant potency order is ascorbic acid $>T$. farfara extract. The $\mathrm{IC}_{50}$ value were 0.92 and $0.34 \mu \mathrm{g} / \mathrm{mL}$ for $T$. farfara extract and ascorbic acid (Table-1).

The above results demonstrate that $T$. farfara extract can inhibit and scavenge the ROS such as $\mathrm{O}_{2}{ }^{\bullet},{ }^{\bullet} \mathrm{OH}$ and $\mathrm{H}_{2} \mathrm{O}_{2}$ effectively. This suggests that T. farfara, a good resource of natural antioxidant, has a potential to be used in the manufacturing of foods and medicines. It is worth noting that $T$. farfara extract exhibited stronger scavenging activity than ascorbic acid on $\mathrm{O}_{2}{ }^{\bullet}$, though those were weaker than ascorbic acid on $\cdot \mathrm{OH}$ and $\mathrm{H}_{2} \mathrm{O}_{2}$.

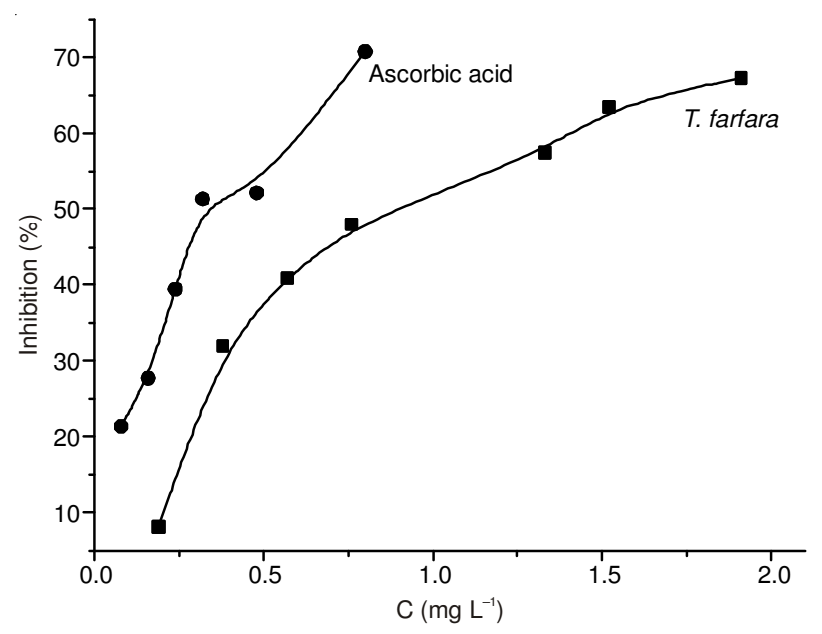

Fig. 5. Scavenging ability on $\mathrm{H}_{2} \mathrm{O}_{2}$ of ascorbic acid and T. farfara. LSD at $p<0.05$

It is known that the superoxide radical is quite harmful to cellular components as a precursor of the more ROS, contributing to the various diseases such as inflammation, mutagenesis, carcinogenesis and tissue injury by circulatory disturbance and aging. In this study, we found that the total flavonoids from T. farfara significantly inhibited superoxide radical generation. This may be attribute partly to its phenolic compounds. Because of their redox properties, hydrogen donors and single oxygen quenchers, phenolics in plants can inhibit free radicals generation and are favorable to human health. Modern pharmacological studies indicated that $75 \%$ alcohol $T$. farfara extract had antiinflammatory effects and its flavonoids had the role of inhibiting mouse lung adenocarcinoma cells ${ }^{14}$, the great potent antioxidant may be an important factor.

\section{ACKNOWLEDGEMENTS}

This work was supported by the Tai'an Technology Development Program (No. 20123071) and the Shandong Province Traditional Chinese Medicine Technology Development Program (No. 2013-258).

\section{REFERENCES}

1. T. Namba, The Encyclopedia of Wakan-Yaku, Hoikusha, Tokyo, Vol. 2, p. 525 (1980).

2. J.H. Ryu, Y.S. Jeong and D.W. Sohn, J. Nat. Prod., 62, 1437 (1999).

3. L. Kokoska, Z. Polesny, V. Rada, A. Nepovim and T. Vanek, J. Ethnopharmacol, 82, 51 (2002).

4. S.-B. Hwang, M.N. Chang, M.L. Garcia, Q.Q. Han, L. Huang, V.F. King, G.J. Kaczorowski and R.J. Winquist, Eur. J. Pharmacol, 141, 269 (1987).

5. E. Haaland, A. Hankey, U. Svanholm, A.M. Duffield, A.T. Balaban and J.C. Craig, Acta. Chem. Scand., 23, 2546 (1969).

6. P.P. Fu, Y.C. Yang, Q. Xia, M.C. Chou, Y.Y. Cui and G. Lin, J. Food Drug Anal., 10, 198 (2002).

7. M.R. Kim, J.Y. Lee, H.H. Lee, D.K. Aryal, Y.G. Kim, S.K. Kim, E.R. Woo and K.W. Kang, Food Chem. Toxicol., 44, 1299 (2006).

8. X. Yao, X. Xu, G. Fan, Y. Qiao, S. Cao and S. Pan, Eur. Food Res. Technol., 229, 743 (2009).

9. C.T. Li, Y.P. Liu, F.C. He and Y. Li, Chin. J. Nat. Med., 10, 260 (2012).

10. B.N. Singh, B.R. Singh, R.L. Singh, D. Prakash, R. Dhakarey, G. Upadhyay and H.B. Singh, Food Chem. Toxicol., 47, 1109 (2009).

11. D. Prakash, B.N. Singh and G. Upadhyay, Food Chem., 102, 1389 (2007).

12. M. Sariahmetoglu, R.A. Wheatley, I. Çakici, I. Kanzik and A. Townshend, Anal. Lett., 36, 749 (2003).

13. C.H. Liu, B.X. Jia, Y.Q. Li, Y.X. Qi, K. Li, Y.R. Guo, Asian J. Chem., 25, 7401 (2013).

14. K.Y. Liu, H.J. Liu, J.Z. Wu and T.J. Zhang, J. Fudan Univ., 48, 125 (2009). 